\title{
Decadal Change of Combination Mode Spatiotemporal Characteristics due to an ENSO Regime Shift
}

\author{
FENG JIANG AND WENJUN ZHANG \\ Collaborative Innovation Center on Forecast and Evaluation of Meteorological Disasters, Key Laboratory of Meteorological \\ Disaster of Ministry of Education, Nanjing University \\ of Information Science and Technology, Nanjing, China \\ MALTE F. STUECKER \\ Department of Oceanography, and International Pacific Research Center, School of Ocean and Earth \\ Science and Technology, University of Hawai' $i$ at Mānoa, Honolulu, Hawaii \\ FEI-FEI JIN \\ Department of Atmospheric Sciences, School of Ocean and Earth Science and Technology, University \\ of Hawai' $i$ at Mānoa, Honolulu, Hawaii
}

(Manuscript received 29 October 2019, in final form 18 March 2020)

\begin{abstract}
Previous studies have shown that nonlinear atmospheric interactions between ENSO and the warm pool annual cycle generates a combination mode (C-mode), which is responsible for the termination of strong El Niño events and the development of the anomalous anticyclone over the western North Pacific (WNP). However, the C-mode has experienced a remarkable decadal change in its characteristics around the early 2000s. The C-mode in both pre- and post-2000 exhibits its characteristic anomalous atmospheric circulation meridional asymmetry but with somewhat different spatial structures and time scales. During 1979-99, the C-mode pattern featured prominent westerly surface wind anomalies in the southeastern tropical Pacific and anticyclonic anomalies over the WNP. In contrast, the C-mode-associated westerly anomalies were shifted farther westward to the central Pacific and the WNP anticyclone was farther westward extended and weaker after 2000. These different C-mode patterns were accompanied by distinct climate impacts over the IndoPacific region. The decadal differences of the $\mathrm{C}$-mode are tightly connected with the ENSO regime shift around 2000; that is, the occurrence of central Pacific (CP) El Niño events with quasi-biennial and decadal periodicities increased while the occurrence of eastern Pacific (EP) El Niño events with quasi-quadrennial periodicity decreased. The associated near-annual combination tone periodicities of the C-mode also changed in accordance with these changes in the dominant ENSO frequency between the two time periods. Numerical model experiments further confirm the impacts of the ENSO regime shift on the C-mode characteristics. These results have important implications for understanding the C-mode dynamics and improving predictions of its climate impacts.
\end{abstract}

\section{Introduction}

El Niño-Southern Oscillation (ENSO), arising from coupled air-sea interactions in the tropical Pacific, has been extensively studied due to its profound global climate impacts (e.g., van Loon and Madden 1981; Rasmusson and Carpenter 1982; Ropelewski and Halpert 1987; Neelin et al. 1998; Wallace et al. 1998; Trenberth and Caron 2000; McPhaden et al. 2006;

Corresponding author: Dr. Wenjun Zhang, zhangwj@nuist.edu.cn
Timmermann et al. 2018). During the past few decades, great progress has been made in understanding ENSO dynamics and its predictability (e.g., Bjerknes 1969; Wyrtki 1975; Cane and Zebiak 1985; Jin 1997; Neelin et al. 1998; Wallace et al. 1998; Capotondi et al. 2015).

One of its prominent characteristics is that ENSO is synchronized with the annual cycle, manifesting in its strong tendency to peak during boreal winter (e.g., Rasmusson and Carpenter 1982; Jin et al. 1994; Tziperman et al. 1994; Larkin and Harrison 2002; An and Jin 2011; Stein et al. 2011, 2014). At the end of the calendar year, 

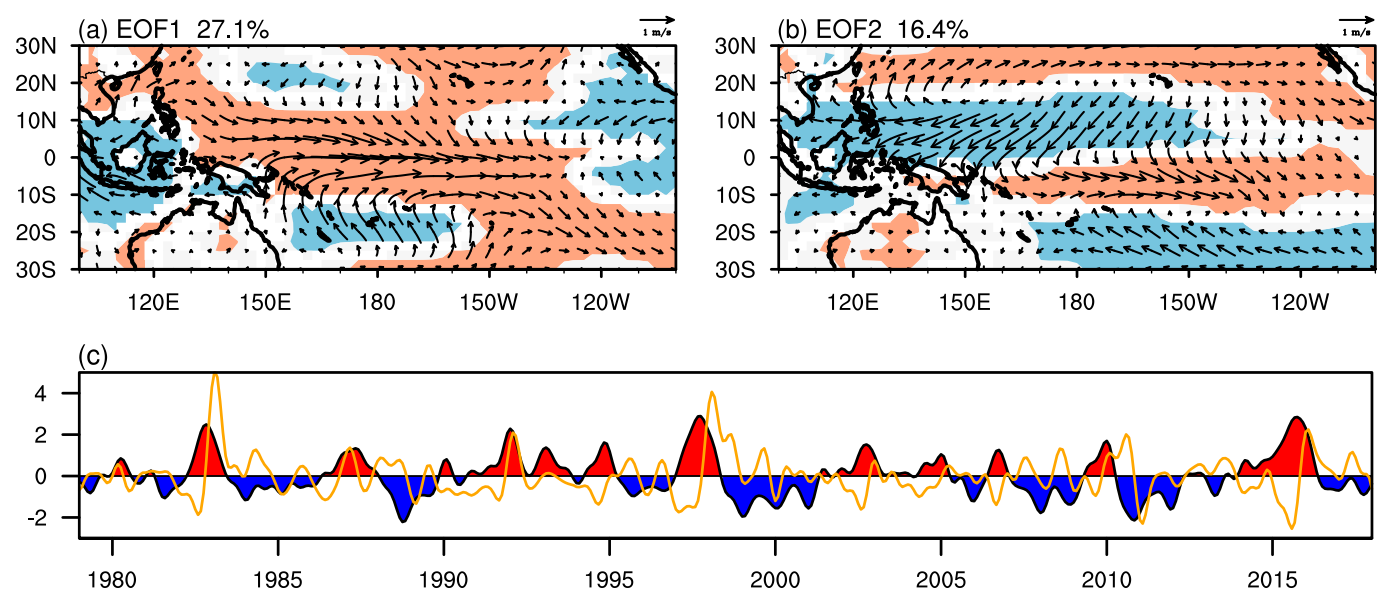

FIG. 1. (a),(b) Leading two EOF spatial patterns of tropical surface wind anomalies (vectors; $\mathrm{m} \mathrm{s}^{-1}$ ) during 19792018. Pink and blue shadings in (a) and (b) indicate statistically significant westerly and easterly anomalies exceeding the $99 \%$ confidence level, respectively. (c) Normalized time coefficients of EOF1 (shading) and EOF2 (orange line). The EOF spatial patterns are obtained by linear regression of the wind anomalies on the corresponding normalized time coefficients.

the southward shift of ENSO-related equatorial zonal wind anomalies contributes to the rapid demise of ENSO events in the following months (e.g., Harrison 1987; Vecchi and Harrison 2006; McGregor et al. 2012). This southward wind shift leads to weakened westerly anomalies on the equator, which allows the equatorial thermocline to return to its normal state by generating upwelling oceanic Kelvin waves in the equatorial eastern Pacific (EP) and discharging equatorial heat content toward the off-equatorial Pacific (e.g., Harrison and Vecchi 1999; Kug et al. 2003; McGregor et al. 2012).

Recent studies have shown that this meridional wind shift can be well captured by the second empirical orthogonal function (EOF) mode (EOF2) of the tropical Pacific $\left(10^{\circ} \mathrm{S}-10^{\circ} \mathrm{N}, 100^{\circ} \mathrm{E}-80^{\circ} \mathrm{W}\right)$ surface wind anomalies (McGregor et al. 2012; Stuecker et al. 2013), which is also referred to as the so-called combination mode (C-mode) (Stuecker et al. 2013, 2015). This C-mode emerges from nonlinear interactions between the warm pool annual cycle and ENSO variability (Stuecker et al. 2013). The ENSO mode (captured by EOF1, $27.1 \%$ of the total variance) exhibits equatorially quasisymmetric westerly anomalies over the central and eastern Pacific, thus representing the direct atmospheric response to ENSO (Fig. 1a). In contrast, the EOF2 (C-mode, $16.4 \%$ of the total variance) pattern is characterized by pronounced meridional atmospheric asymmetry with an anomalous anticyclone over the western North Pacific (WNP) and southward-shifted westerly anomalies over the central tropical Pacific (Fig. 1b). The C-mode contributes to the rapid termination of strong El Niño events and is crucial to the development of the anomalous anticyclone over the WNP during the El Niño mature and decay phases (Stuecker et al. 2013, 2015). The C-mode usually enters its peak phase during early boreal spring, approximately one to three months after ENSO peaks, which plays an important role for precipitation over Indo-Pacific region (Stuecker et al. 2013; Zhang et al. 2015b, 2016a; Jiang et al. 2019).

Besides, a new type of El Niño event has occurred frequently over the central Pacific (CP) in recent decades, differing dramatically from conventional El Niño events, which has its sea surface temperature (SST) anomaly (SSTA) center in the eastern Pacific (e.g., Larkin and Harrison 2005; Ashok et al. 2007; Weng et al. 2007; Kao and Yu 2009; Kug et al. 2009; Yeh et al. 2009; Ren and Jin 2011). Since the early 2000s, CP El Niño has occurred more often while EP El Niño has become less common compared to the pre- 2000 period, in which El Niño is dominated by the EP type (e.g., Yeh et al. 2009; Horii et al. 2012; McPhaden 2012; Zhang et al. 2014). A similar decadal change in the zonal location of SSTAs cannot be easily detected for La Niña events, although La Niña can also be separated into two types based on its spatial structure and associated climate impacts (e.g., Cai and Cowan 2009; Zhang et al. 2015a, 2019). Accompanied by this decadal regime change of the El Niño spatial structure, El Niño intensity has weakened and its main periodicity shifted from quasi-quadrennial (QQ) to quasi-biennial (QB) and decadal (e.g., Yeh et al. 2009; McPhaden et al. 2011; Hu et al. 2013; Ren et al. 2013; Xiang et al. 2013; Sullivan et al. 2016). This decadal shift in El Niño characteristics around 2000 has been documented in many previous studies as an ENSO 
regime shift (e.g., Horii et al. 2012; McPhaden 2012; Hu et al. 2013; Zhang et al. 2014).

It is natural to expect that the ENSO-associated C-mode also exhibits a decadal change along with the ENSO regime shift. However, thus far it is not clear to what extent the ENSO-related C-mode characteristics as well as its climate impacts have changed. Here we proceed to document these changes. Our analyses of both the observations and targeted modeling experiments document that an observed decadal change of C-mode characteristics can be attributed to the ENSO regime shift. In this study, we investigate this decadal change of C-mode characteristics and its associated climate impacts. The data and methodology are introduced in section 2. In section 3 , the characteristics of the C-mode before and after 2000 are investigated and compared. Then the results from targeted numerical model simulations to further confirm the impacts of the ENSO regime shift on the C-mode are documented in section 4 . In section 5 , we document the climate impacts associated with the $\mathrm{C}$-mode in different periods. Finally, a summary and discussion are provided in section 6 .

\section{Data and methodology}

\section{a. Observations}

The global sea ice and SST analysis (1979-2018) from the Hadley Centre (HadISST) provided by the Met Office Hadley Centre (Rayner et al. 2003) is used in this study. The precipitation data from the global precipitation product from the Climate Prediction Center Merged Analysis of Precipitation (CMAP; 1979-2018) are utilized to investigate ENSO-related precipitation impacts. To examine the variation of ENSO-related wind anomalies, we use monthly 10-m winds (19792018) from the National Centers for Environmental Prediction-National Center for Atmospheric Research (NCEP-NCAR) reanalysis dataset (Kalnay et al. 1996). The horizonal resolution is $1^{\circ} \times 1^{\circ}$ for the SST datasets and $2.5^{\circ} \times 2.5^{\circ}$ for the wind and precipitation datasets.

Anomalies for all variables are computed by removing the monthly mean climatology (1979-2018). The linear trends are removed from all datasets to avoid possible influences associated with global warming, and a 6month low-pass Butterworth filter is applied to exclude possible impacts from subseasonal variability. We emphasize that the qualitative conclusions remain the same when we use unfiltered data. The Niño-3.4 index, calculated as the area-averaged SSTAs in the Niño-3.4 region $\left(5^{\circ} \mathrm{S}-5^{\circ} \mathrm{N}, 120^{\circ}-170^{\circ} \mathrm{W}\right)$, is used to characterize ENSO. El Niño events are identified according to the
Climate Prediction Center's definition: If the 3-month running mean of the Niño-3.4 index is larger than $0.5^{\circ} \mathrm{C}$ for five consecutive months, this year will be categorized as an El Niño year. With this method we identify $10 \mathrm{El}$ Niño events in the time period of the study. We further identify four EP $(1982,1991,1997,2015)$ and six CP (1986, 1994, 2002, 2004, 2006, 2009) El Niño events based on the Niño-3 and Niño-4 indices, which are calculated as the area-averaged SSTAs in the Niño-3 $\left(5^{\circ} \mathrm{S}-\right.$ $\left.5^{\circ} \mathrm{N}, 90^{\circ}-150^{\circ} \mathrm{W}\right)$ and Niño- $4\left(5^{\circ} \mathrm{S}-5^{\circ} \mathrm{N}, 120^{\circ}-170^{\circ} \mathrm{W}\right)$ region, respectively. El Niño events with Niño-3 greater than Niño-4 in winter (December-February) are defined as EP El Niño events while those with Niño-4 greater than Niño-3 are identified as CP El Niño events. Limited ENSO samples are accepted for composites and other statistical analyses due to the relatively high SST anomaly pattern stability associated with different ENSO events (e.g., Weng et al. 2007; McGregor et al. 2013; Zhang et al. 2015a, 2016b). All statistical significance tests are performed using a two-tailed Student's $t$ test (Wilks 2006).

\section{b. Model experiments}

The numerical model used here is the Geophysical Fluid Dynamics Laboratory (GFDL) global Atmospheric Model, version 2.1 (AM2.1), with a horizontal resolution of $2.5^{\circ}$ longitude $\times 2^{\circ}$ latitude. To further confirm the observed differences in $\mathrm{C}$-mode characteristics related to EP and CP ENSO-dominated regimes, four sensitivity experiments (EX-2yr-EP, EX-4yr-EP, EX-2yr-CP, and $\mathrm{EX}-4 \mathrm{yr}-\mathrm{CP}$ ) were performed by using an idealized sinusoidal EP and CP ENSO forcing with 2- and 4-yr periodicities, respectively. Composited EP El Niño SSTAs during period 1 (1979-99, P1 hereafter) and CP El Niño composites during period 2 (2000-18, P2 hereafter) over the tropical Pacific $\left(20^{\circ} \mathrm{S}-20^{\circ} \mathrm{N}, 150^{\circ} \mathrm{E}-90^{\circ} \mathrm{W}\right)$ were used to derive the idealized SSTA forcing patterns for the EX-EP (EX-2yr-EP, EX-4yr-EP) and EX-CP (EX-2yr-CP and EX-4yr-CP) experiments, respectively. The qualitative conclusions remain the same when using composited EP and CP El Niño events for the entire period instead. SSTAs outside the forcing area are set to zero and only the positive loading in the forcing region is used. Then these ENSO patterns are multiplied by idealized sinusoidal time series to derive the time evolution of the EP and CP ENSO-related SSTAs. We force the model with repeated sinusoidal 2-yr periodicity SSTAs in the EX-2yr-EP and EX-2yr$\mathrm{CP}$ experiments and with a sinusoidal 4-yr periodicity in the EX-4yr-EP and EX-4yr-CP experiments, respectively. With these idealized 2- and 4-yr periodicities, all ENSO peak phases will occur aligned with boreal winter. The simulations are integrated for 


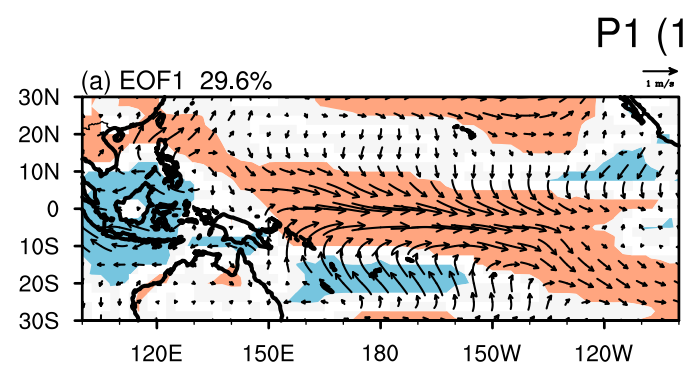

P1 (1979-1999)
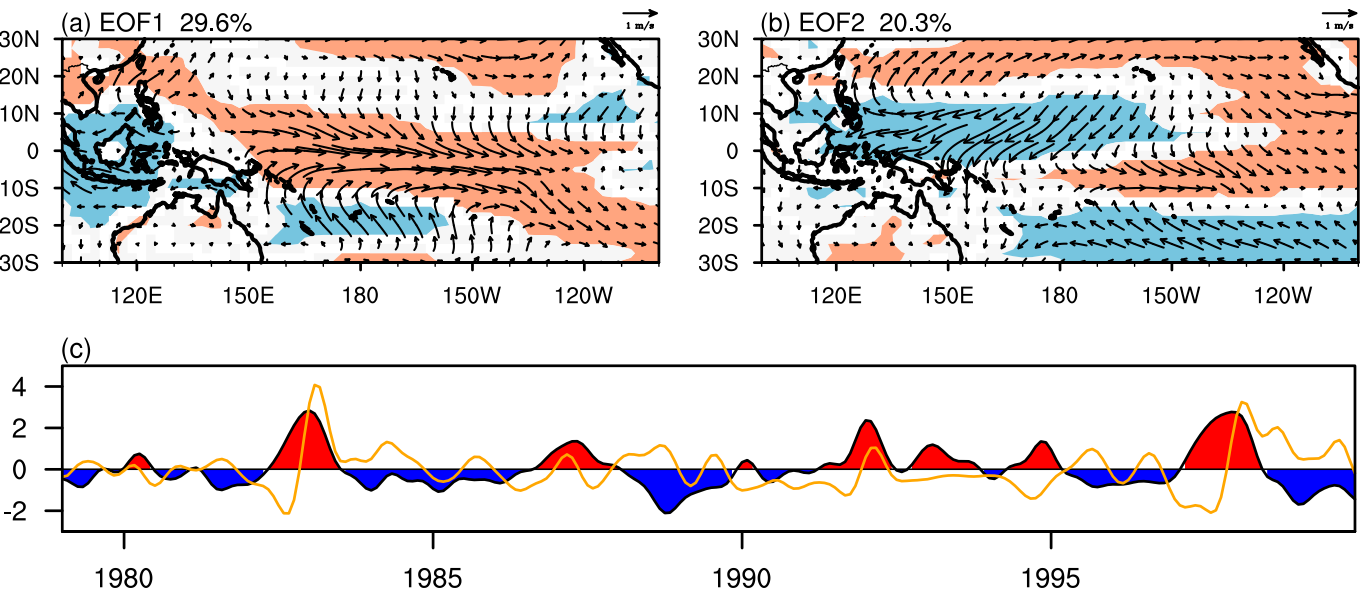

P2 (2000-2018)
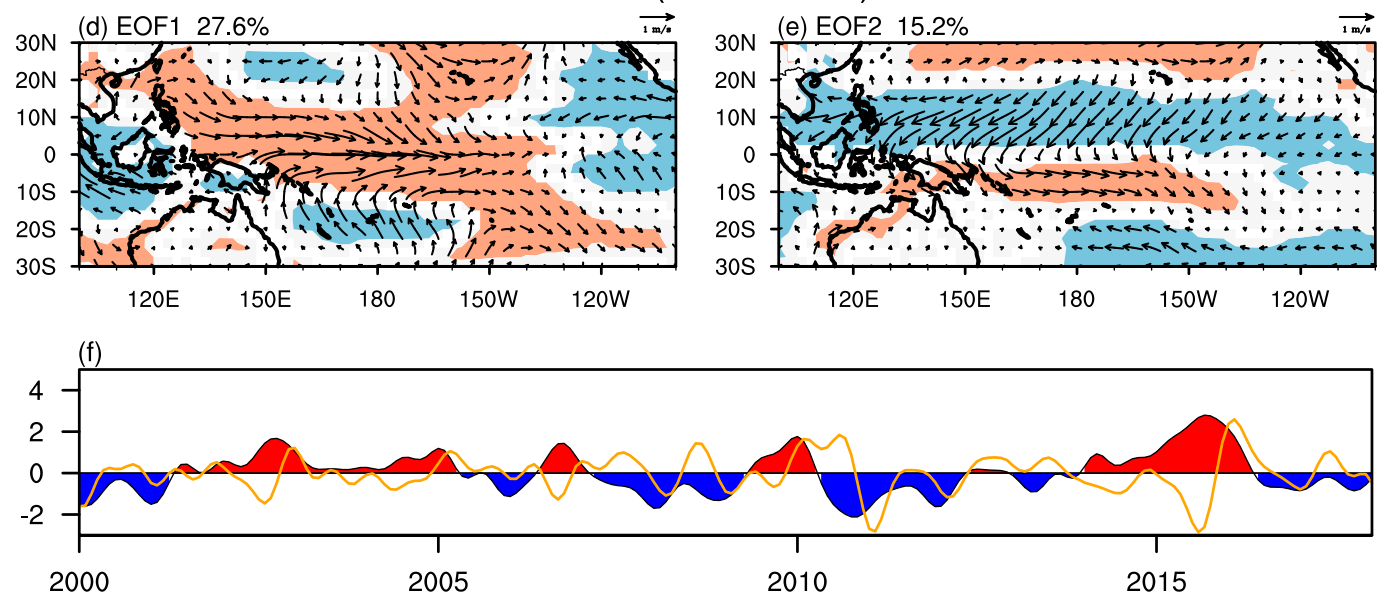

FIG. 2. Leading two EOF spatial patterns of tropical surface wind anomalies (vectors; $\mathrm{m} \mathrm{s}^{-1}$ ) during (a),(b) P1 and (d),(e) P2. Pink and blue shadings in (a), (b), (d), and (e) indicate statistically significant westerly and easterly anomalies exceeding the $99 \%$ confidence level, respectively. The corresponding normalized time coefficients of EOF1 (shading) and EOF2 (orange line) are shown during (c) P1 and (f) P2.

20 years in the repeating 2 -yr forcing runs and for 40 years in the repeating 4-yr forcing experiments, yielding 10 idealized EP and CP ENSO cycles for each simulation.

\section{C-mode spatiotemporal characteristics in the different time periods}

Observations show that tropical Pacific SST variability was dominated by EP El Niño events in the pre-2000 period and by the CP El Niño in the post-2000 period (see introduction). To investigate possible decadal changes of C-mode characteristics due to this ENSO regime shift, we separate the entire time period of this study into two periods ( $\mathrm{P} 1$ and $\mathrm{P} 2$ ). EOF analyses are then conducted on the monthly tropical surface wind anomalies for P1 (Figs. 2a-c) and P2 (Figs. 2d-f), respectively. EOF1 in P1 (EOF1_P1) and P2 (EOF1_P2) account for $29.6 \%$ and $27.6 \%$ of the total variance, respectively. The leading normalized time coefficients (also often referred to as principal components) of EOF1 have high correlation coefficients $(\sim 0.92)$ with the Niño-3.4 indices in these two periods (Figs. 2c,d), capturing ENSO variability well. The corresponding spatial patterns for P1 (Fig. 2b) and P2 (Fig. 2d) feature similar equatorially quasi-symmetric westerly anomalies over the tropical Pacific, both resembling the EOF1 pattern obtained over the entire period (Fig. 1a) despite some differences in the zonal location. During P1, strong equatorial westerly anomalies prevail from $150^{\circ} \mathrm{E}$ to $120^{\circ} \mathrm{W}$, while these are shifted farther westward during P2 (Figs. 2a,d). These different wind patterns are 


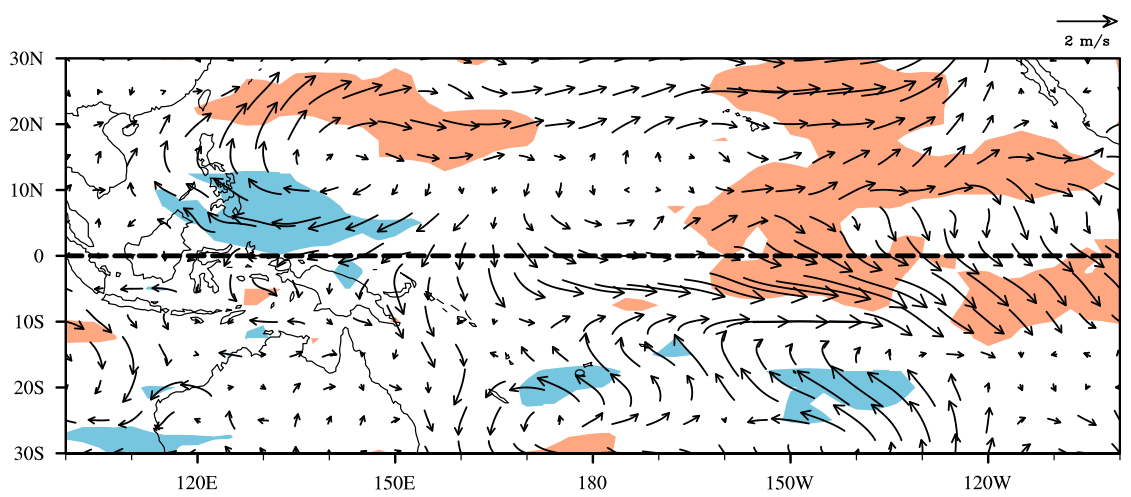

FIG. 3. Wind anomaly differences between FMA-mean composites for El Niño events in P1 and P2. Pink and blue shadings indicate statistically significant westerly and easterly anomalies exceeding the $90 \%$ confidence level, respectively.

consistent with more frequent occurrences of $\mathrm{CP} \mathrm{El}$ Niño events (and decrease of EP El Niño event occurrences) during the last two decades (e.g., McPhaden 2012; Xiang et al. 2013), considering that CP El Niño events are accompanied by a farther westward-shifted air-sea action center compared to EP El Niño events.

Interestingly, large differences can be detected when comparing the EOF2 patterns in P1 (Fig. 2b) and P2 (Fig. 2e). EOF2 in P1 (EOF2_P1) and P2 (EOF2_P2) account for $20.3 \%$ and $15.2 \%$ of the total variance, respectively. During P1 (Fig. 2b), the EOF2 pattern shows pronounced westerly anomalies in the southeastern tropical Pacific and low-level anticyclonic circulation anomalies over the WNP, which is similar to the EOF2 pattern for the entire period (Fig. 1b) and corresponds to the typical C-mode pattern (Stuecker et al. 2013). The EOF2 during P2 also captures the C-mode main features: the southward shift of westerly anomalies and the WNP anticyclonic anomalies. In comparison to P1, the EOF2 in $\mathrm{P} 2$ exhibits westward-shifted westerly anomalies south of the equator (by $\sim 30^{\circ}$ of longitude) and farther zonally extended easterly anomalies north of the equator. In addition, it shows a farther westwardextended WNP anticyclone compared to the EOF2 of P1 (Fig. 2b). The observed difference between the EOF2 patterns during $\mathrm{P} 1$ and $\mathrm{P} 2$ can also be seen in the wind anomaly difference between February-April (FMA)-mean composites during El Niño events in P1 and P2 (Fig. 3). The FMA period is chosen because the C-mode typically displays large amplitude during early boreal spring (Fig. 4).

Previous studies have shown that the southward shift of equatorial westerly anomalies and the associated WNP anticyclonic circulation appear mainly during EP El Niño events based on EOF analyses for the entire period (Zhang et al. 2015b, 2016a). The EOF results for P2 (Figs. 2e,f) indicate that the CP El Niño-dominated regime is also accompanied by a southward shift of westerly anomalies and a development of the WNP anticyclone but with different spatial patterns. The $\mathrm{C}$-mode reaches its peak usually about one to three months after the EP El Niño peak (Fig. 4a). For EP El Niño events, the time coefficient of EOF1 (describing temporal ENSO evolution) starts developing from boreal spring and peaks in winter, leading that of EOF2 by approximately one to three months. A similar relationship between EOF1 and EOF2 can also be seen during CP El Niño events in P2. The composited time coefficient of EOF1_P2 (Fig. 4b) exhibits an analogous temporal evolution as that of EOF1_P1 (Fig. 4a) with a small difference in amplitude. Correspondingly, the composited time coefficients of EOF2_P2 reverses its sign abruptly from negative to positive during late winter and enters its peak phase around February of the El Niño decaying phase, similar to the time coefficient of EOF2_P1. This EOF2 time evolution describes the abrupt southward shift of tropical Pacific westerly anomalies during the CP El Niño-dominated P2. Interestingly, there is a secondary (albeit statistically insignificant) peak of the time coefficients of EOF2 in the following late summer, possibly owing to the subsequent phase shift from a retreating El Niño event to a developing La Niña condition and air-sea coupling induced persistence of the WNP anticyclone (Stuecker et al. 2015).

We next illustrate the relationship of the ENSO regime shift with the C-mode change based on our theoretical understanding of the ENSO-C-mode relationship. The theoretical approximations for the C-mode (Stuecker et al. 2013, 2015) are constructed in the form of $\mathrm{EOF} 1 \_\mathrm{P} 1(t) \times \cos \left(\omega_{a} t-\varphi\right)$ for $\mathrm{P} 1$ and EOF1_ $\mathrm{P} 2(t) \times \cos \left(\omega_{a} t-\varphi\right)$ for $\mathrm{P} 2$, respectively. These approximations are obtained from the first-order term in nonlinear ENSO/annual cycle interactions, where $\omega_{a}$ 

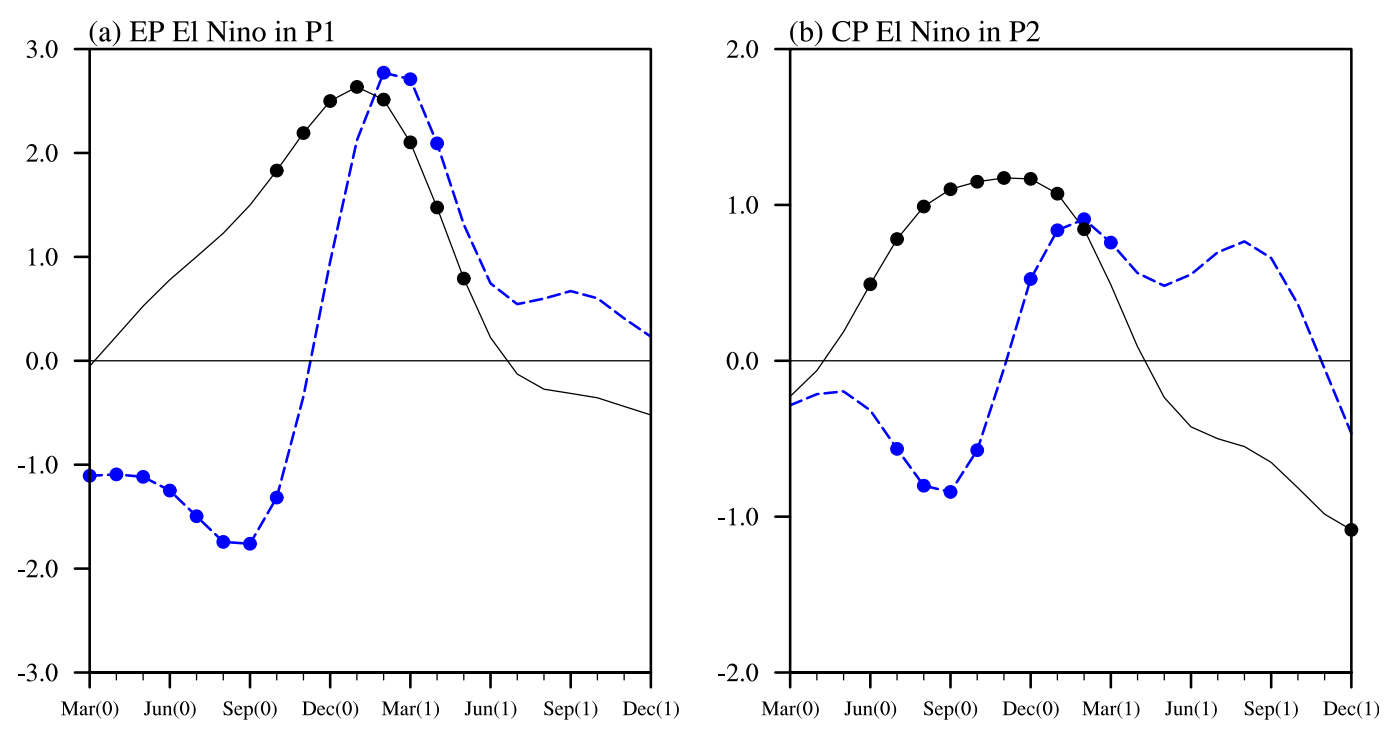

FIG. 4. Composited monthly evolutions of normalized time coefficients of EOF1 (black) and EOF2 (blue) for (a) EP El Niño events in P1 and (b) CP El Niño events in P2. Solid circles indicate composited values that exceed the $90 \%$ statistical significance level.

denotes the angular frequency of the annual cycle and $\varphi$ its phase. The correlation coefficients between the theoretical $\mathrm{C}$-mode indices and time coefficient of EOF2 in P1 (Fig. 5a) and P2 (Fig. 5b) are 0.56 and 0.72, respectively (exceeding the $99 \%$ statistical significance level). These results indicate that the observed $\mathrm{C}$-mode variability can be regarded as the superposition of the theoretical C-mode (i.e., a modulation of ENSO by the annual cycle), enhanced persistence of C-mode induced atmospheric anomalies by air-sea coupling (Stuecker et al. 2015; Zhang et al. 2016b), and unforced internal atmospheric variability that projects onto the $\mathrm{C}$-mode pattern.
Next, as the intrinsic ENSO time scale has changed in association with the regime shift, we hypothesize that the C-mode temporal characteristics should also have changed given their close relationship. As elucidated in Stuecker et al. (2013), the C-mode exhibits most of its spectral variance at the ENSO/annual cycle difference $\left(1-f_{e}\right)$ and sum $\left(1+f_{e}\right)$ tones, where 1 represents the annual cycle frequency and $f_{e}$ the frequency (frequency band) of ENSO, which are near-annual time scales due to the ENSO interannual time scale. The question is, however, how detectable these C-mode spectral characteristic changes are in the presence of atmospheric noise.

(a) PC2_P1 (black) and theoretical C-mode in P1 (orange)

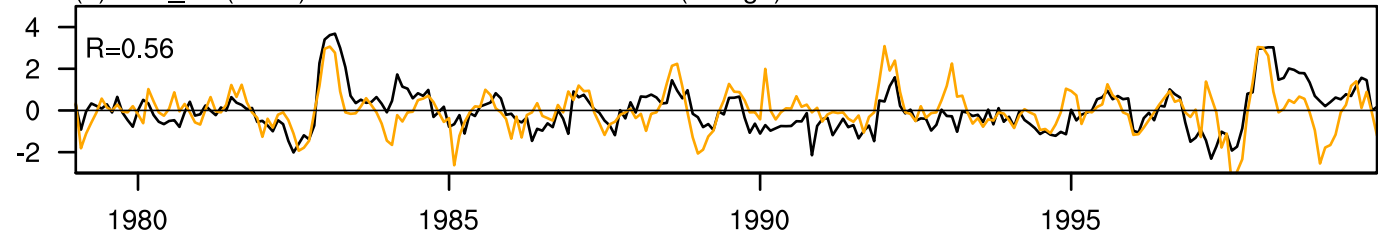

(b) PC2 P2 (black) and theoretical C-mode in P2 (orange)

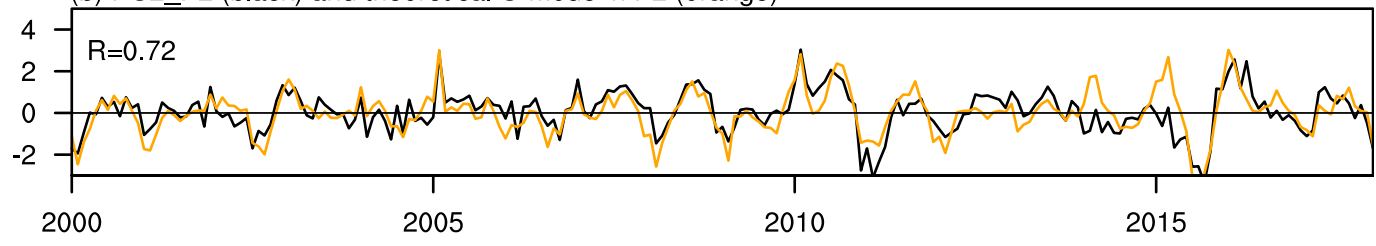

FIG. 5. Normalized time coefficients of EOF2 (black) and theoretical C-mode index (orange) during (a) P1 and (b) P2. 

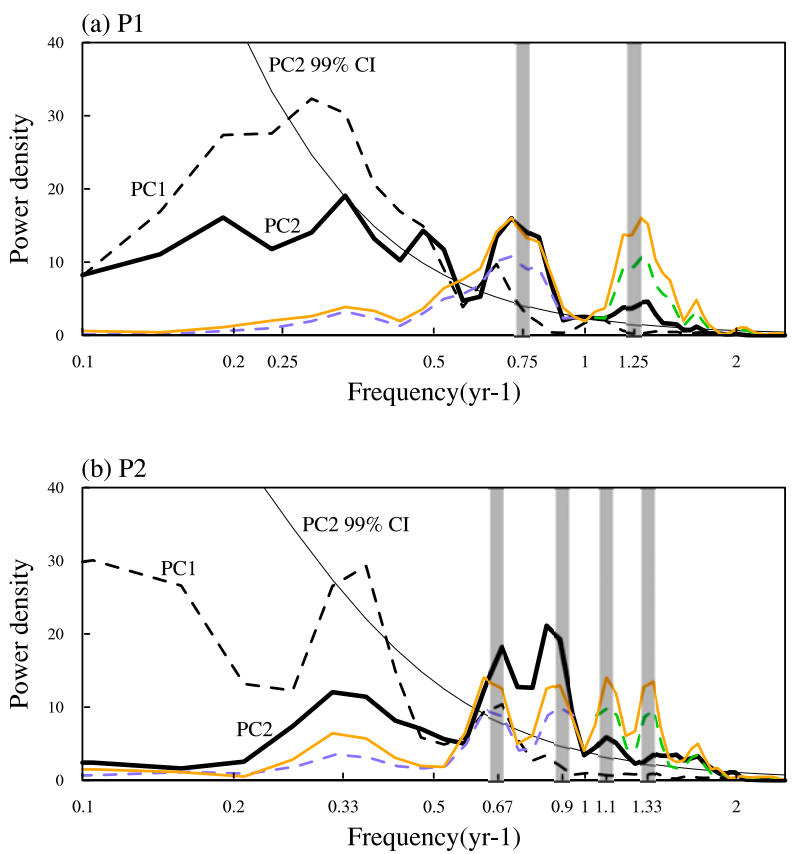

FIG. 6. Fast Fourier transform (FFT) power spectra for time coefficients of EOF1 (dashed thick black) and EOF2 (solid thick black) during (a) P1 and (b) P2. The time coefficients of EOF1 are shifted to $1-f$ (dashed blue) and $1+f$ (dashed green) and scaled by a factor of $1 / 3$ to illustrate the EOF 2 combination tone frequencies. The thin black lines indicate the $99 \%$ confidence interval (CI) for the time coefficient of EOF2. The orange line indicates the power spectra for theoretical C-mode index (scaled by a factor of 2 ). The thick gray vertical lines indicate the approximate frequency peaks at $1-f_{e}$ and $1+f_{e}\left[0.75\right.$ and $1.25 \mathrm{yr}^{-1}$ in (a) and 0.67, 0.9, 1.1, and $1.33 \mathrm{yr}^{-1}$ in (b)].

As shown in the spectral analyses in Fig. 6, ENSO variability (the time coefficient of EOF1_P1) exhibits pronounced QQ time scales $\left(f_{e} \approx 0.25 \mathrm{yr}^{-1}\right)$ during $\mathrm{P} 1$, while it (the time coefficient of EOF1_P2) displays QB time scales $\left(f_{e} \approx 0.33 \mathrm{yr}^{-1}\right)$ superimposed on decadal low-frequency variability $\left(\sim 10-\mathrm{yr}, f_{e} \approx 0.1 \mathrm{yr}^{-1}\right)$ during $\mathrm{P} 2$. As detected in previous studies, EP El Niño shows strong QQ periodicity while CP El Niño exhibits QB characteristics (e.g., Weng et al. 2007; Kao and Yu 2009; Kug et al. 2009). Besides the ENSO-dominant interannual variability, CP El Niño indices also show strong decadal variability (e.g., Ren and Jin 2013; Xiang et al. 2013; Sullivan et al. 2016). The distinct periodicities seen in PC1 of EP-dominant P1 and CP-dominant P2 can be attributed to the contrasts in the main periodicities associated with EP and CP El Niño. Correspondingly, the time coefficient of EOF2_P1 exhibits statistically significant spectral peaks at around $0.75 \mathrm{yr}^{-1}$ ( $\sim 16$ month) and $1.25 \mathrm{yr}^{-1}$ ( $\sim 10$ month), consistent with a $\sim 1 \pm f_{e}$ shift of the ENSO QQ frequencies. In contrast, the time coefficient of EOF2_P2 shows four different near- annual frequency peaks, which correspond approximately to $0.67 \mathrm{yr}^{-1}$ ( $\sim 18$ month), $0.9 \mathrm{yr}^{-1}$ ( $\sim 13 \mathrm{month}$ ), $1.1 \mathrm{yr}^{-1}$ ( $\sim 11$ month), and $1.33 \mathrm{yr}^{-1}$ ( $\sim 9$ month). Here, the $1-f_{e}$ peaks are more detectable than the $1+f_{e}$ peaks (the sum tones being only marginally detectable in the presence of the background noise). Possible reasons include difficulties to obtain a robust spectral estimate from relatively short observational records, higher-order atmospheric nonlinearities, and the reddening effects due to air-sea interactions (see discussions in Stuecker et al. 2013, 2015). However, in agreement with the frequency peaks of the time coefficients of EOF1_P2 and EOF2_P2, the associated theoretical C-mode indices also exhibit pronounced $1-f_{e}$ and $1+f_{e}$ frequency peaks in both $\mathrm{P} 1$ and $\mathrm{P} 2\left(f_{e}=\right.$ $0.25 \mathrm{yr}^{-1}$ in $\mathrm{P} 1, f_{e}=0.33$ and $0.1 \mathrm{yr}^{-1}$ in $\mathrm{P} 2$; orange lines in Fig. 6).

\section{Numerical model experiment results}

The above observed analyses suggest that the C-mode pattern and its temporal characteristics have experienced significant decadal changes in accordance with the ENSO regime shift around 2000. To further confirm our arguments based on the observation, we conduct four sensitivity experiments with different SSTAs (Fig. 7a in EX-2yr-EP and EX-4yr-EP runs, Fig. 7b in EX-2yr-CP and EX-4yr-CP runs) and periodicities (see experimental designs in section 2).

We conduct EOF analyses on the monthly tropical surface wind anomalies in these four runs. As we can see in Fig. 8, the 2- and 4-yr idealized ENSO forcings can derive similar C-mode dynamics, both showing significant near-annual variability in their difference tone and sum tone ( 0.5 and $1.5 \mathrm{yr}^{-1}$ for 2 -yr runs, 0.75 and 1.25 for 4-yr runs). Other periodicities (e.g., 2.5, 5, and 10 years) are tested to force the model and similar conclusions can be drawn.

The 2- and 4-yr period ENSO forcings also derive similar atmospheric responses in the spatial pattern, so only the EOF patterns in the 2-yr runs (EX-2yr-EP and EX-2yr-CP) are shown here. These two simulations (Fig. 9) well reproduce the observed ENSO and the $\mathrm{C}$-mode related wind anomaly patterns during $\mathrm{P} 1$ and $\mathrm{P} 2$ (Fig. 2). In the EX-2yr-EP run, there are strong equatorially quasi-symmetric westerly anomalies associated with $\mathrm{PC} 1$, which prevails from $150^{\circ} \mathrm{E}$ to $120^{\circ} \mathrm{W}$ (Fig. 9a). As to the EOF2 pattern (Fig. 9b), there are significant meridionally asymmetric wind anomalies in the tropical Pacific, characterized by westerly anomalies in the southeastern Pacific and easterly anomalies in the WNP. For the EX-2yr-CP run with weaker SSTA amplitude and westward-shifted zonal location (Fig. 9c), 

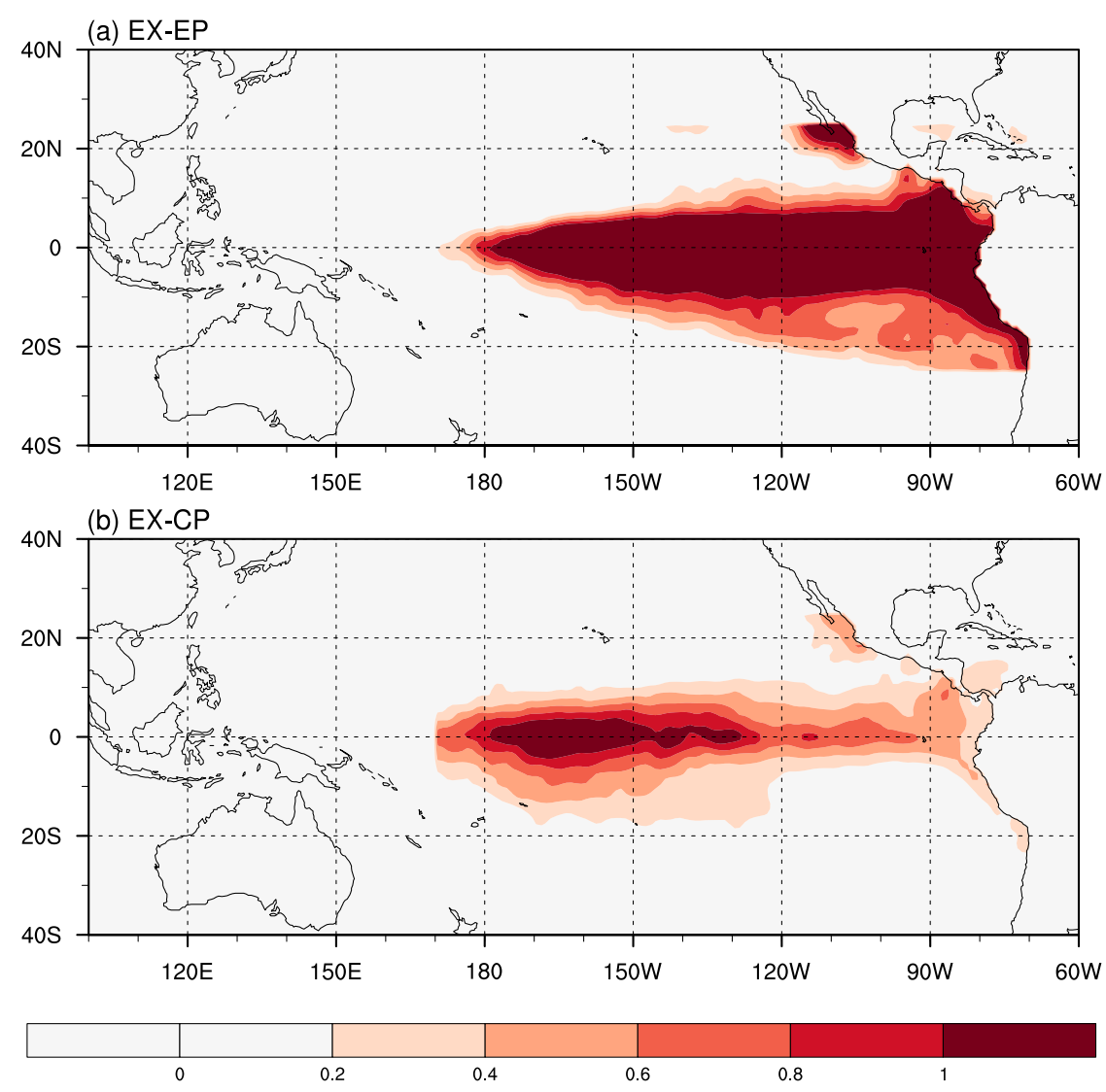

FIG. 7. SSTA patterns used as boundary forcing in the (a) EX-EP and (b) EX-CP experiments.

the strong tropical wind anomaly pattern associated with PC1 resembles that in the observation (Fig. 2d). The EOF2 pattern in the EX-2yr-CP run (Fig. 9d) also exhibits similar equatorial meridional asymmetry of wind anomalies compared to the observation (Fig. 2e), featuring easterly anomalies north of the equator and westerly anomalies south of the equator, which are both confined to the central Pacific. It can be seen that the observed spatiotemporal differences are well reproduced by these experiments, suggesting that the ENSO regime shift is mainly responsible for the decadal change in the C-mode spatiotemporal characteristics.

\section{Distinct climate impacts associated with different C-mode characteristics}

To examine whether also the C-mode related climate impacts have changed around 2000, we compare the surface circulation and precipitation anomalies associated with the two leading EOFs during P1 (Figs. 10a,b) and P2 (Figs. 10c,d), respectively. The direct ENSOrelated impacts (EOF1 regressions) during both $\mathrm{P} 1$ and P2 (Figs. 10a,c) feature quasi-symmetric surface circulation and precipitation anomaly patterns with respect to the equator, displaying the classic Gill response to an equatorial central Pacific heating source. The only difference is a slight westward shift in the zonal location of the anomalies during P1 compared to P2, consistent with the ENSO-related tropical surface wind pattern shift (Figs. 2a,d).

For the PC2 regressions (Figs. 10b,d), the surface circulation and precipitation anomalies are highly meridionally asymmetric, showing the characteristic C-mode signals over the central Pacific and WNP. Both of them exhibit an anomalous cyclone (associated with enhanced precipitation) over the southern central Pacific and an anomalous anticyclone (associated with reduced precipitation) over the WNP. However, obvious discrepancies can be observed in their spatial distributions. During P1, the positive precipitation anomaly center in the central equatorial Pacific extends from the date line to the South American coast (Fig. 10b). In contrast, this positive precipitation center is located farther westward with an absence of positive precipitation anomalies over the eastern equatorial Pacific during P2 (Fig. 10d). Over the Indo-Pacific region, the WNP anticyclone is stronger 


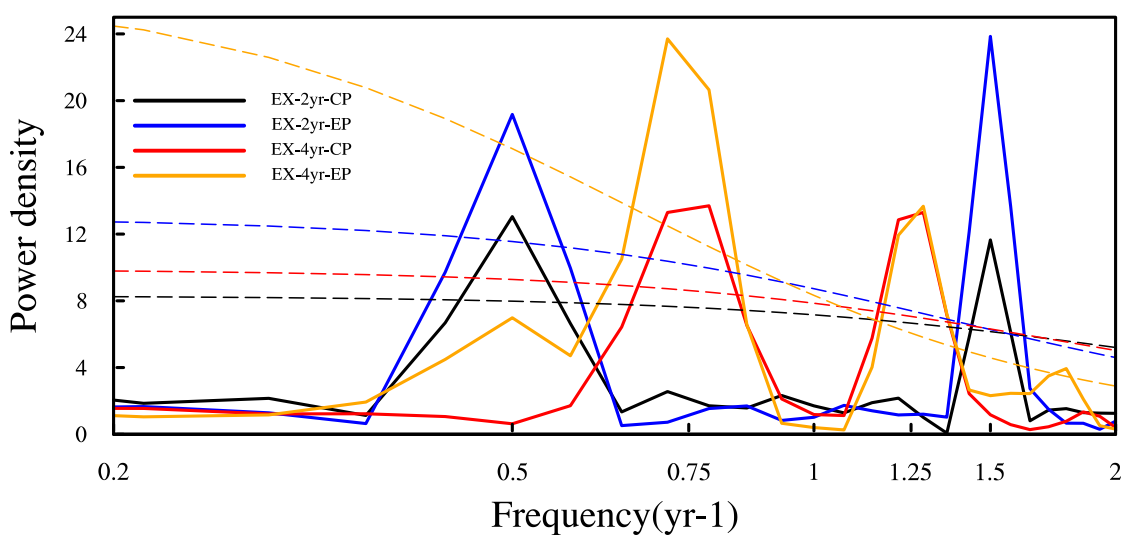

FIG. 8. FFT power spectra for the time coefficient of EOF2 in EX-2yr-EP (solid black), EX2yr-EP (solid blue), EX-4yr-EP (solid red), and EX-4yr-EP (solid orange). Dashed lines indicate the corresponding $99 \%$ confidence intervals (CI).

during P1, leading to enhanced moisture transports northeastward to East Asia and thus enhanced precipitation along the East Asian subtropical jet (Fig. 10b). In contrast, during $\mathrm{P} 2$, this anticyclonic system elongates more zonally (extending into the Arabian Sea) with weaker amplitude in the WNP region (Fig. 10d). The western boundary of the WNP anticyclone in P2 extends farther westward by $\sim 50^{\circ}$ compared to the western boundary in P1. Accordingly, there are large-scale precipitation deficits in the northern tropical area from the Bay of Bengal to the coast of South America in P2. This zonally extended anticyclonic circulation system transports less moisture to East Asia and is thereby associated with reduced positive precipitation anomalies over southern China and adjacent seas. Simultaneously, negative precipitation anomalies are evident over the Bay of Bengal and northern part of the Maritime Continent $\left(\sim 90^{\circ}-120^{\circ} \mathrm{E}, 0^{\circ}-20^{\circ} \mathrm{N}\right)$, roughly opposite to the response in P1.

We next investigate the reconstructed precipitation anomalies over the tropical Pacific based on the PCs of different periods to examine their differences. Here the boreal spring season (March-May) is our focus since the C-mode reaches its peak amplitude usually in this season. As shown in Fig. 11a, positive precipitation anomalies exist over the southeastern tropical Pacific and
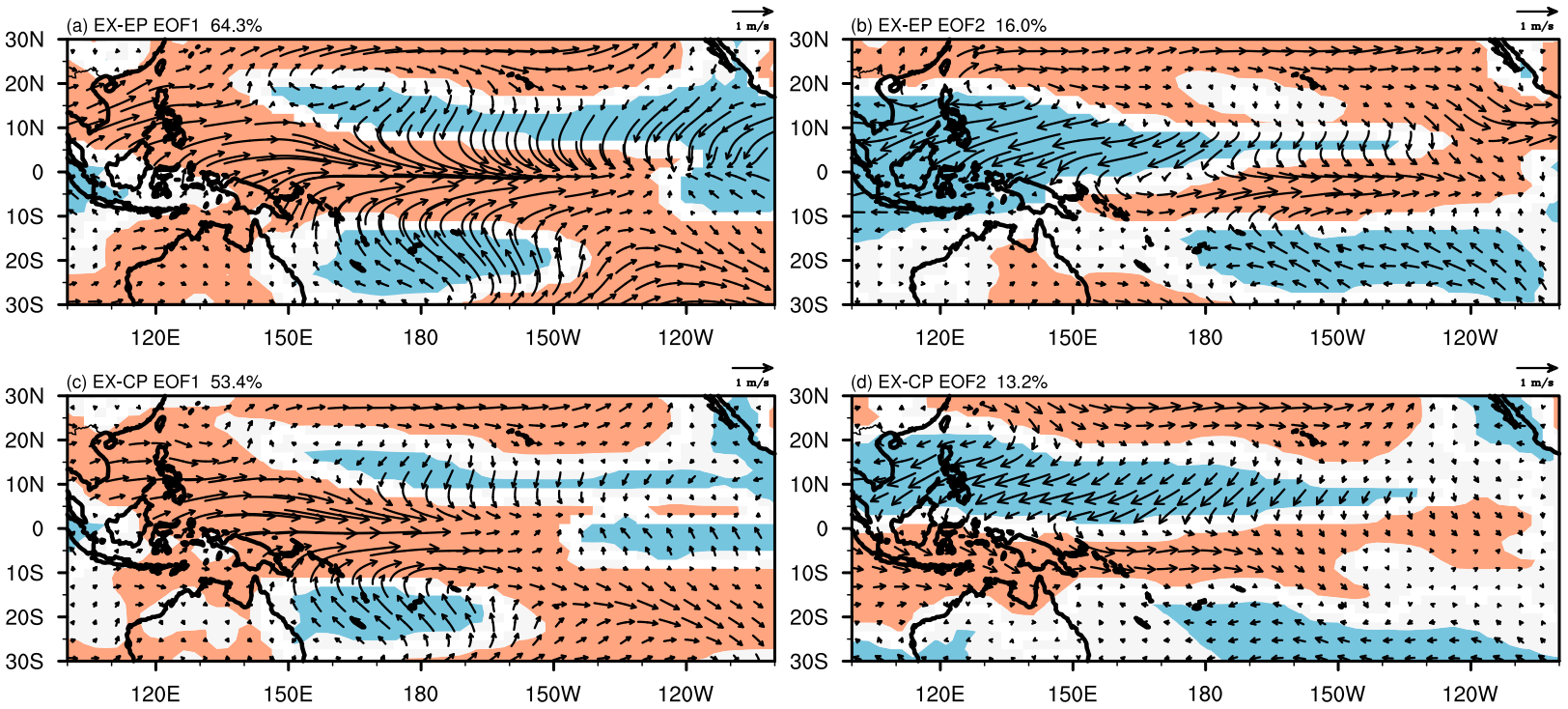

FIG. 9. The leading two EOF spatial patterns of the tropical surface wind anomalies (vectors; $\mathrm{m} \mathrm{s}^{-1}$ ) in (a),(b) EX-2yr-EP and (c),(d) EX-2yr-CP. Pink and blue shadings indicate statistically significant westerly and easterly anomalies exceeding the $99 \%$ confidence level, respectively. 

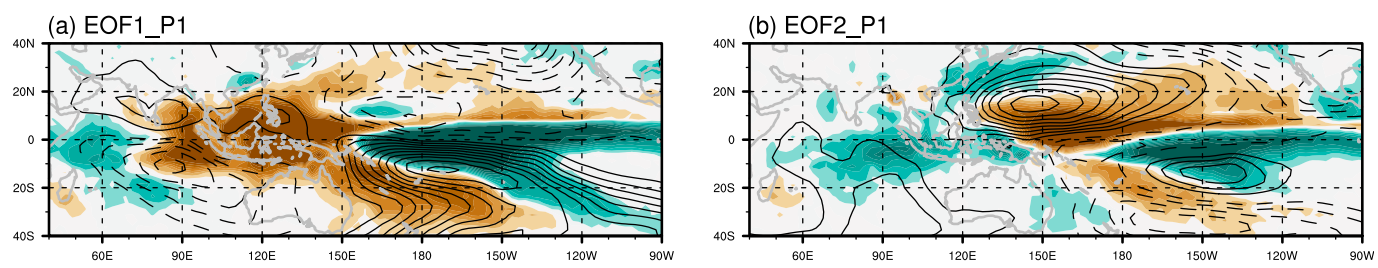

(c) EOF1_P2
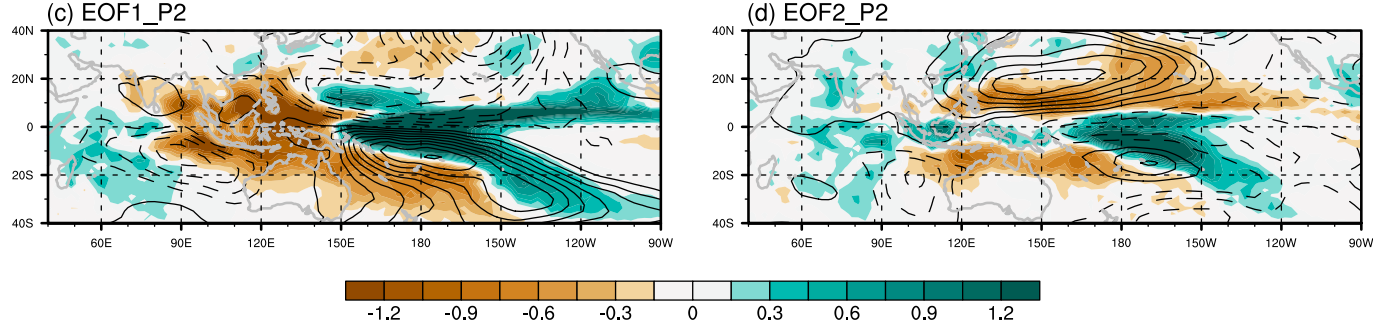

FIG. 10. Precipitation anomalies (shading; $\mathrm{mm} \mathrm{day}^{-1}$ ) and surface wind streamfunction anomalies (contours; $1.5 \times 10^{-5} \mathrm{~m}^{2} \mathrm{~s}^{-1}$ ) regressed onto normalized time coefficients of (a) EOF1_P1, (b) EOF2_P1, (c) EOF1_P2, and (d) EOF2_P2.

negative precipitation anomalies over the WNP during the decaying spring of EP El Niño events in P1. The spring precipitation anomalies are reconstructed by using the time coefficients of EOF1_P2 and EOF2_P2 calculated for the entire period (Fig. 11b) and P1 only (Fig. 11c), respectively. Both of the reconstructions can well capture the observed precipitation anomaly pattern. Similarly, we also composite CP El Niño events in
P2 (Fig. 11d), in which the precipitation anomaly pattern shows a westward shift of both the positive and negative precipitation anomaly centers compared to P1. The leading two PCs for the entire period fail to reproduce the precipitation anomalies associated with the $\mathrm{CP} \mathrm{El}$ Niño events in P2 (Fig. 11e). In contrast, the precipitation anomaly pattern can be well reconstructed by using the time coefficients of EOF1_P2 and EOF2_P2
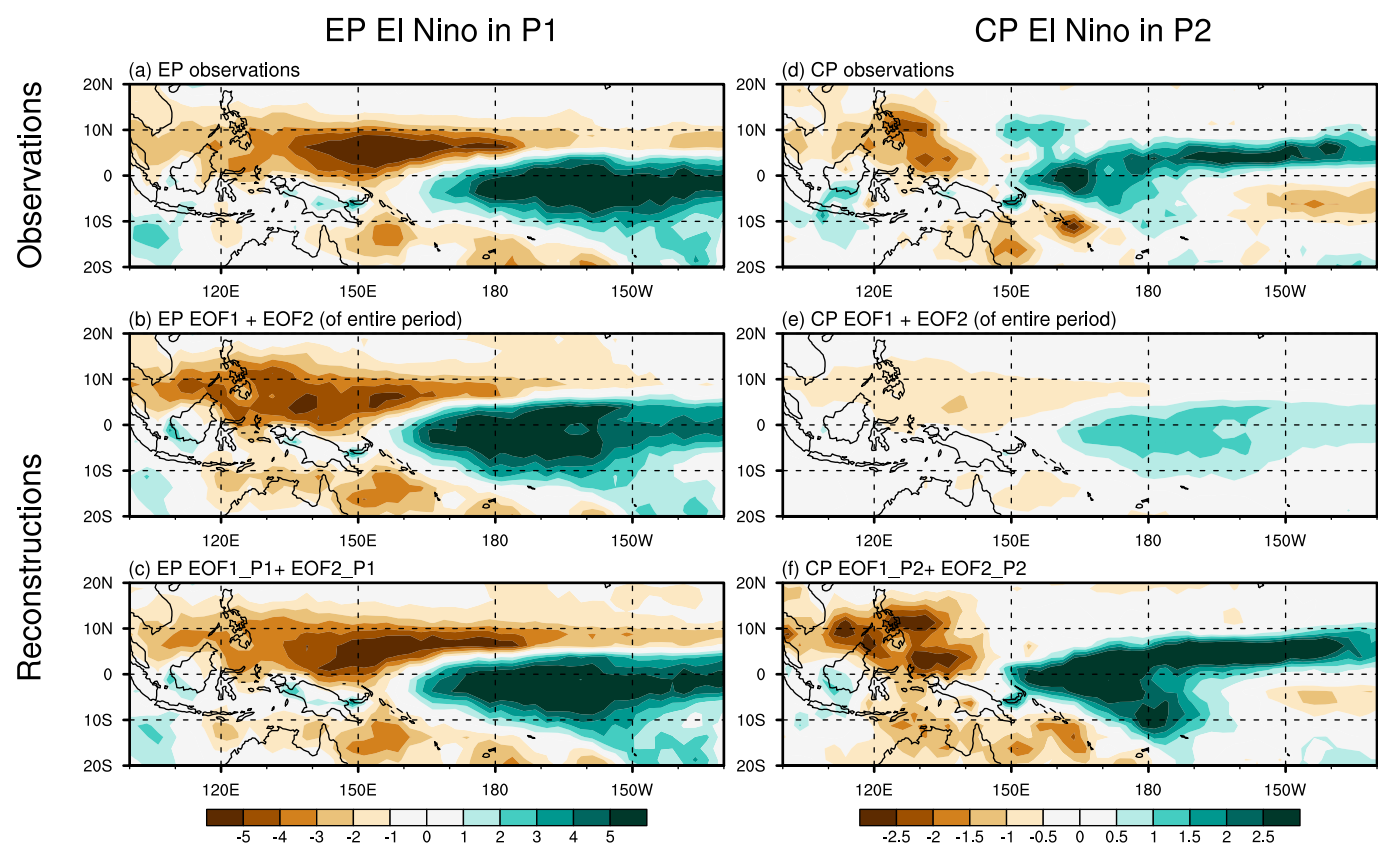

FIG. 11. Composited spring precipitation anomalies (shading; $\mathrm{mm} \mathrm{day}^{-1}$ ) during (a) EP El Niño events in P1 and (d) CP El Niño events in P2. Reconstructed precipitation anomalies during EP El Niño events in P1 based on the time coefficients of EOF1 and EOF2 for (b) the entire period and (c) P1. Reconstructed precipitation anomalies during CP El Niño events in P2 based on the time coefficients of EOF1 and EOF2 for (e) the entire period and (f) P2. 
(Fig. 11f). As discussed in the introduction, the atmospheric response is dominated by EP El Niño events when considering the whole time period (Fig. 1). Thus, the EP El Niño precipitation anomaly pattern is well reconstructed based on the leading two PCs for both the entire period and P1 (Figs. 11b,c). In contrast, CP El Niño events occurred much more frequently in $\mathrm{P} 2$ and its associated $\mathrm{C}$-mode exhibits a pronounced change in its pattern, explaining why the spring precipitation anomaly for CP El Niño can only be reconstructed using the PCs derived from P2 (Figs. 11e,f).

\section{Summary and discussion}

Previous studies have shown that the C-mode plays an essential role in the termination of El Niño events as well as the development of the anomalous WNP anticyclone (e.g., Stuecker et al. 2013, 2015; Zhang et al. 2015b, 2016a). Here we find that due to the ENSO regime shift around 2000, the C-mode has experienced decadal changes in its spatiotemporal characteristics. Before 2000, the C-mode pattern is characterized by pronounced westerly surface wind anomalies in the southeastern Pacific and anticyclonic anomalies over the WNP. After 2000, the C-mode-associated wind anomalies exhibit a different spatial structure with westwardshifted anomalous westerlies south of the equator and farther zonally extended anomalous easterlies north of the equator. Concurrently, the western boundary of the anomalous WNP anticyclone after 2000 extends farther westward compared to pre-2000. This decadal change of the C-mode pattern can be attributed to the ENSO regime shift that occurred around 2000, manifested as the shift of the dominant El Niño type from EP El Niño to CP El Niño. The C-mode also exhibits different temporal characteristics before and after 2000 along with the ENSO periodicity shift from dominant QQ variability in P1 to the superposition of QQ and decadal variability in P2 (e.g., Horii et al. 2012; McPhaden 2012; $\mathrm{Hu}$ et al. 2013). During P1, the C-mode exhibits statistically significant spectral peaks at around 16 and 10 months. In contrast, during $\mathrm{CP}$-dominant $\mathrm{P} 2$, the $\mathrm{C}$-mode spectrum exhibits four different near-annual peaks, which are approximately at 18, 13,11, and 9 months. These correspond to the expected $1 \pm f_{e}$ combination tones resulted from $\mathrm{QB}$ and decadal variability. Targeted numerical model experiments further confirm this spatiotemporal change of the C-mode due to the ENSO regime shift.

In addition, C-mode-associated climate impacts have also changed around 2000 due to the decadal change of the $\mathrm{C}$-mode characteristics. The $\mathrm{C}$-mode response generally features low-level cyclonic anomalies (associated with enhanced precipitation) to the south of the equator over the central Pacific and an anomalous anticyclone (associated with reduced precipitation) over the WNP (Figs. 10b,d). Differences in this pattern can be observed over the equatorial Pacific during these two periods. The positive precipitation anomaly center in the central Pacific during P2 was located farther westward compared to P1. Over the Indo-Pacific region, the WNP anticyclone was stronger during P1. In contrast, it was more elongated zonally with weaker amplitude and extended farther westward during P2. This different spatial structure of the anomalous WNP anticyclone contributes to distinct precipitation responses over the IndoPacific region.

A few recent studies suggested that the frequency of CP El Niño events might further increase under projected global warming scenarios (e.g., Yeh et al. 2009; McPhaden et al. 2011; Cai et al. 2015). The future occurrence ratio of CP El Niño to EP El Niño would lead to different C-mode impacts in a warming world.

Acknowledgments. This work was supported by the National Nature Science Foundation of China (41675073), the National Key Research and Development Program on Monitoring, Early Warning and Prevention of Major Natural Disaster (2018YFC1506002), and the SOA Program on Global Change and Air-Sea interactions (GASI-IPOVAI-03).

\section{REFERENCES}

An, S.-I., and F.-F. Jin, 2011: Linear solutions for the frequency and amplitude modulation of ENSO by the annual cycle. Tellus, 63A, 238-243, https://doi.org/10.1111/j.1600-0870.2010.00482.x.

Ashok, K., S. K. Behera, S. A. Rao, H. Weng, and T. Yamagata, 2007: El Niño Modoki and its possible teleconnection. J. Geophys. Res., 112, C11007, https://doi.org/10.1029/ 2006JC003798

Bjerknes, J., 1969: Atmospheric teleconnections from the equatorial Pacific. Mon. Wea. Rev., 97, 163-172, https://doi.org/ 10.1175/1520-0493(1969)097<0163:ATFTEP $>2.3$.CO;2.

Cai, W., and T. Cowan, 2009: La Niña Modoki impacts Australia autumn rainfall variability. Geophys. Res. Lett., 36, L12805, https://doi.org/10.1029/2009GL037885.

— - and Coauthors, 2015: ENSO and greenhouse warming. Nat. Climate Change, 5, 849-859, https://doi.org/10.1038/ nclimate2743.

Cane, M. A., and S. E. Zebiak, 1985: A theory for El Niño and the Southern Oscillation. Science, 228, 1085-1087, https://doi.org/ 10.1126/science.228.4703.1085.

Capotondi, A., and Coauthors, 2015: Understanding ENSO diversity. Bull. Amer. Meteor. Soc., 96, 921-938, https://doi.org/ 10.1175/BAMS-D-13-00117.1.

Harrison, D. E., 1987: Monthly mean island surface winds in the central tropical Pacific and El Niño events. Mon. Wea. Rev., 115, 3133-3145, https://doi.org/10.1175/1520-0493(1987) 115<3133:MMISWI>2.0.CO;2. 
and G. A. Vecchi, 1999: On the termination of El Niño. Geophys. Res. Lett., 26, 1593-1596, https://doi.org/10.1029/ 1999GL900316.

Horii, T., I. Ueki, and K. Hanawa, 2012: Breakdown of ENSO predictors in the 2000s: Decadal changes of recharge/discharge-SST phase relation and atmospheric intraseasonal forcing. Geophys. Res. Lett., 39, 10707, https://doi.org/10.1029/2012GL051740.

Hu, Z. Z., A. Kumar, H. L. Ren, H. Wang, and F. F. Jin, 2013: Weakened interannual variability in the tropical Pacific Ocean since 2000. J. Climate, 26, 2601-2613, https://doi.org/10.1175/ JCLI-D-12-00265.1.

Jiang, F., W. Zhang, X. Geng, M. F. Stuecker, and C. Liu, 2019: Impacts of central Pacific El Niño on southern China spring precipitation controlled by its longitudinal position. J. Climate, 32, 7823-7836, https://doi.org/10.1175/JCLI-D-19-0266.1.

Jin, F.-F., 1997: An equatorial recharge paradigm for ENSO. Part I: Conceptual model. J. Atmos. Sci., 54, 811-829, https://doi.org/ 10.1175/1520-0469(1997)054<0811:AEORPF $>2.0 . C O ; 2$.

— J. D. Neelin, and M. Ghil, 1994: El Niño on the devil's staircase: Annual subharmonic steps to chaos. Science, 264, 70-72, https://doi.org/10.1126/science.264.5155.70.

Kalnay, E., and Coauthors, 1996: The NCEP/NCAR 40-Year Reanalysis Project. Bull. Amer. Meteor. Soc., 77, 437-471, https:// doi.org/10.1175/1520-0477(1996)077<0437:TNYRP>2.0.CO;2

Kao, H. Y., and J. Y. Yu, 2009: Contrasting eastern-Pacific and central-Pacific types of ENSO. J. Climate, 22, 615-632, https:// doi.org/10.1175/2008JCLI2309.1.

Kug, J.-S., I.-S. Kang, and S.-I. An, 2003: Symmetric and antisymmetric mass exchanges between the equatorial and offequatorial Pacific associated with ENSO. J. Geophys. Res., 108, 3284, https://doi.org/10.1029/2002JC001671.

— , F.-F. Jin, and S.-I. An, 2009: Two types of El Niño events: Cold tongue El Niño and warm pool El Niño. J. Climate, 22, 1499-1515, https://doi.org/10.1175/2008JCLI2624.1.

Larkin, N. K., and D. E. Harrison, 2002: ENSO warm (El Niño) and cold (La Niña) event life cycles: Ocean surface anomaly patterns, their symmetries, asymmetries, and implications. J. Climate, 15, 1118-1140, https://doi.org/10.1175/1520-0442(2002) 015<1118:EWENOA>2.0.CO;2.

$\longrightarrow$, and — 2005: Global seasonal temperature and precipitation anomalies during El Niño autumn and winter. Geophys. Res. Lett., 32, L16705, https://doi.org/10.1029/2005GL022860.

McGregor, S., A. Timmermann, N. Schneider, M. F. Stuecker, and M. H. England, 2012: The effect of the South Pacific convergence zone on the termination of El Niño events and the meridional asymmetry of ENSO. J. Climate, 25, 5566-5586, https://doi.org/10.1175/JCLI-D-11-00332.1.

—, N. Ramesh, P. Spence, M. H. England, M. J. McPhaden, and A. Santoso, 2013: Meridional movement of wind anomalies during ENSO events and their role in event termination. Geophys. Res. Lett., 40, 749-754, https://doi.org/ 10.1002/grl.50136.

McPhaden, M. J., 2012: A 21st century shift in the relationship between ENSO SST and warm water volume anomalies. Geophys. Res. Lett., 39, 9706, https://doi.org/10.1029/ 2012 GL051826.

, S. E. Zebiak, and M. H. Glantz, 2006: ENSO as an integrating concept in earth science. Science, 314, 1740-1745, https:// doi.org/10.1126/science.1132588.

, T. Lee, and D. McClurg, 2011: El Niño and its relationship to changing background conditions in the tropical Pacific Ocean. Geophys. Res. Lett., 38, L15709, https://doi.org/10.1029/ 2011GL048275.
Neelin, J. D., D. S. Battisti, A. C. Hirst, F. F. Jin, Y. Wakata, T. Yamagata, and S. E. Zebiak, 1998: ENSO theory. J. Geophys. Res., 103, 14261-14290, https://doi.org/10.1029/ 97JC03424.

Rasmusson, E. M., and T. H. Carpenter, 1982: Variations in tropical sea surface temperature and surface wind fields associated with the Southern Oscillation/El Niño. Mon. Wea. Rev., 110, 354-384, https://doi.org/10.1175/1520-0493(1982)110<0354: VITSST $>2.0 . \mathrm{CO} ; 2$.

Rayner, N. A., D. E. Parker, E. B. Horton, C. K. Folland, L. V. Alexander, D. P. Rowell, E. C. Kent, and A. Kaplan, 2003: Global analyses of sea surface temperature, sea ice, and night marine air temperature since the late nineteenth century. J. Geophys. Res., 108, 4407, https://doi.org/10.1029/ 2002JD002670.

Ren, H.-L., and F.-F. Jin, 2011: Niño indices for two types of ENSO. Geophys. Res. Lett., 38, L04704, https://doi.org/10.1029/ 2010GL046031.

— and - 2013: Recharge oscillator mechanisms in two types of ENSO. J. Climate, 26, 6506-6523, https://doi.org/10.1175/ JCLI-D-12-00601.1.

,-- , M. F. Stuecker, and R. Xie, 2013: ENSO regime change since the late $1970 \mathrm{~s}$ as manifested by two types of ENSO. $J$. Meteor. Soc. Japan, 91, 835-842, https://doi.org/10.2151/ jmsj.2013-608.

Ropelewski, C. F., and M. S. Halpert, 1987: Global and regional scale precipitation patterns associated with the El Niño/Southern Oscillation. Mon. Wea. Rev., 115, 1606-1626, https://doi.org/ 10.1175/1520-0493(1987)115<1606:GARSPP>2.0.CO;2.

Stein, K., A. Timmermann, and N. Schneider, 2011: Phase synchronization of the El Niño-Southern Oscillation with the annual cycle. Phys. Rev. Lett., 107, 128501, https://doi.org/ 10.1103/PhysRevLett.107.128501.

,,--- F.-F. Jin, and M. F. Stuecker, 2014: ENSO seasonal synchronization theory. J. Climate, 27, 5285-5310, https://doi.org/10.1175/JCLI-D-13-00525.1.

Stuecker, M. F., A. Timmermann, F. F. Jin, S. McGregor, and H. L. Ren, 2013: A combination mode of the annual cycle and the El Niño/Southern Oscillation. Nat. Geosci., 6, 540-544, https:// doi.org/10.1038/ngeo1826.

__ , F.-F. Jin, A. Timmermann, and S. McGregor, 2015: Combination mode dynamics of the anomalous Northwest Pacific anticyclone. J. Climate, 28, 1093-1111, https://doi.org/ 10.1175/JCLI-D-14-00225.1.

Sullivan, A., J.-J. Luo, A. C. Hirst, D. Bi, W. Cai, and J. He, 2016: Robust contribution of decadal anomalies to the frequency of central-Pacific El Niño. Sci. Rep., 6, 38540, https://doi.org/ 10.1038/srep38540.

Timmermann, A., and Coauthors, 2018: El Niño-Southern Oscillation complexity. Nature, 559, 535-545, https://doi.org/ 10.1038/s41586-018-0252-6.

Trenberth, K. E., and J. M. Caron, 2000: The Southern Oscillation revisited: Sea level pressures, surface temperatures, and precipitation. J. Climate, 13, 4358-4365, https://doi.org/10.1175/ 1520-0442(2000)013<4358:TSORSL>2.0.CO;2.

Tziperman, E., L. Stone, M. A. Cane, and H. Jarosh, 1994: El Niño chaos: Overlapping of resonances between the seasonal cycle and the Pacific Ocean-atmosphere oscillator. Science, 264, 7274, https://doi.org/10.1126/science.264.5155.72.

van Loon, H., and R. A. Madden, 1981: The Southern Oscillation. Part I: Global associations with pressure and temperature in northern winter. Mon. Wea. Rev., 109, 1150-1162, https://doi.org/ 10.1175/1520-0493(1981)109<1150:TSOPIG > 2.0.CO;2. 
Vecchi, G. A., and D. E. Harrison, 2006: The termination of the 1997/98 El Niño. Part I: Mechanisms of oceanic change. J. Climate, 19, 2633-2646, https://doi.org/10.1175/JCLI3776.1.

Wallace, J. M., E. M. Rasmusson, T. P. Mitchell, V. E. Kousky, E. S. Sarachik, and H. von Storch, 1998: On the structure and evolution of ENSO-related climate variability in the tropical Pacific: Lessons from TOGA. J. Geophys. Res., 103, 1424114 259, https://doi.org/10.1029/97JC02905.

Weng, H., K. Ashok, S. K. Behera, S. A. Rao, and T. Yamagata, 2007: Impacts of recent El Niño Modoki on dry/wet conditions in the Pacific rim during boreal summer. Climate Dyn., 29, 113-129, https://doi.org/10.1007/s00382-007-0234-0.

Wilks, D. S., 2006: Statistical Methods in the Atmospheric Sciences. 2nd ed. International Geophysics Series, Vol. 100, Academic Press, 648 pp.

Wyrtki, K., 1975: El Niño-The dynamic response of the equatorial Pacific Ocean to atmospheric forcing. J. Phys. Oceanogr., 5, 572-584, https://doi.org/10.1175/1520-0485(1975)005<0572: ENTDRO $>2.0 . \mathrm{CO} ; 2$.

Xiang, B., B. Wang, and T. Li, 2013: A new paradigm for predominance of standing central Pacific warming after the late 1990s. Climate Dyn., 41, 327-340, https://doi.org/10.1007/s00382-012-1427-8.

Yeh, S. W., J. S. Kug, B. Dewitte, M. H. Kwon, B. P. Kirtman, and F. F. Jin, 2009: El Niño in a changing climate. Nature, 462, 674 674, https://doi.org/10.1038/nature08546.
Zhang, W., F.-F. Jin, and A. Turner, 2014: Increasing autumn drought over southern China associated with ENSO regime shift. Geophys. Res. Lett., 41, 4020-4026, https://doi.org/ 10.1002/2014GL060130.

— , L. Wang, B. Xiang, L. Qi, and J. He, 2015a: Impacts of two types of La Niña on the NAO during boreal winter. Climate Dyn., 44, 1351-1366, https://doi.org/10.1007/s00382-0142155-z.

- , H. Li, F.-F. Jin, M. F. Stuecker, A. G. Turner, and N. P. Klingaman, 2015b: The annual-cycle modulation of meridional asymmetry in ENSO's atmospheric response and its dependence on ENSO zonal structure. J. Climate, 28, 5795-5812, https://doi.org/10.1175/JCLI-D-14-00724.1.

,-- M. F. Stuecker, F.-F. Jin, and A. G. Turner, 2016a: A new understanding of El Niño's impact over East Asia: Dominance of the ENSO combination mode. J. Climate, 29, 4347-4359, https://doi.org/10.1175/JCLI-D-15-0104.1.

, and Coauthors, 2016b: Unraveling El Niño's impact on the East Asian monsoon and Yangtze River summer flooding. Geophys. Res. Lett., 43, 11375-11382, https://doi.org/10.1002/ 2016GL071190.

Z. Wang, M. F. Stuecker, A. G. Turner, F.-F. Jin, and X. Geng, 2019: Impact of ENSO longitudinal position on teleconnections to the NAO. Climate Dyn., 52, 257-274, https:// doi.org/10.1007/s00382-018-4135-1. 